\title{
Experimental Study of The Driving-characteristic of Occupational Drivers and Non-occupational Drivers
}

\author{
Cao HE ${ }^{1, a}$, Bin CHEN ${ }^{1, b}$, Qing CHEN ${ }^{1, c}$ and Jian Bo WANG ${ }^{1, d}$
}

\author{
${ }^{1}$ Si Chuan Communication Vocational technology College Sichuan college key laboratory of road \\ traffic safety. No. 208, Liu Tai Road, Wenjiang District, Chengdu, China \\ a249882871@qq.com, ${ }^{\mathrm{b}}$ cb1103@tom.com, ${ }^{\mathrm{c}}$ hcsiu 999@163.com, ${ }^{\mathrm{d}}$ wjianbo2000@126.com
}

\begin{abstract}
Keywords: Occupational Drivers, Non-occupational Drivers, Static detection, Dynamic test
\end{abstract}
\begin{abstract}
In order to enable non-occupational drivers are better able to participate in road traffic, to ensure road traffic safety and establish the driving guidance method for non-occupational drivers' driver training to provide a more effective way to achieve the purpose of reducing traffic accidents, the random sampling drivers are used for the static test and dynamic real vehicle testing. Tests have been completed with driving adaptive testing equipment, dynamic eye tracking device detector and dynamic physiological detector. To mathematical statistics and mathematical modeling based on theoretical approaches, two types of experimental data was used to analyze differences in the adaptability of the driver and differences in intake of external information and physiological and psychological in different types of traffic conditions. The results will help to reduce traffic accidents involving non-occupational drivers.
\end{abstract}

\section{Introduction}

In various types of road traffic accidents, the driver take full responsibility for the primary responsibility for the accident accounted for more than $70 \%$ to $80 \%$, showing that the driver is the dominant factor of the traffic safety. The large number of studies have found that Part of the driver than other drivers more prone to accidents, and the high probability of repeated accidents, mainly closely related to drivers' driving adaptation. Occupational drivers shoulder the life and property safety of the people in the process of driving, driving adaptive requirements much higher than the non-occupational drivers.

Using static testing and dynamic testing method of combining, we researched the driving characteristics of occupational drivers and non-occupational drivers. Static tests include : night visual acuity, dynamic visual acuity, stereoscopic vision, depth perception, color discrimination, a complex reaction, manipulation skills, speed estimation, etc.; dynamic tests include : eye movement, ECG .

\section{Experimental design}

Static detection Objects. Occupational driver driving the adaptive test samples a total of 216; non-occupational driver's total number of samples is 97.

Dynamic test objects. Occupational drivers' and non-occupational driver's total number of samples is 38. The drivers' information was shown in the Table 1.

Table 1. Dynamic test driver information

\begin{tabular}{c|c|c|c|c|c|c|c|c|c|c|c|c|c|c|c}
\hline \multicolumn{9}{c|}{ Occupational driver } & \multicolumn{1}{c}{ Non-occupational driver } \\
\hline $\begin{array}{c}\mathbf{N} \\
\mathbf{O}\end{array}$ & Sex & Age & $\begin{array}{c}\text { Driving } \\
\text { age }\end{array}$ & NO. & Sex & Age & $\begin{array}{c}\text { Driving } \\
\text { age }\end{array}$ & NO. & Sex & Age & $\begin{array}{c}\text { Driving } \\
\text { age }\end{array}$ & NO. & Sex & Age & $\begin{array}{c}\text { Drivin } \\
\text { g age }\end{array}$ \\
\hline 1 & M & 45 & 28 & 11 & M & 40 & 22 & 1 & M & 26 & 6 & 11 & M & 26 & 4 \\
\hline 2 & M & 43 & 10 & 12 & M & 55 & 35 & 2 & M & 56 & 32 & 12 & M & 28 & 6 \\
\hline 3 & M & 31 & 11 & 13 & M & 37 & 12 & 3 & M & 39 & 12 & 13 & M & 22 & 2 \\
\hline 4 & M & 37 & 17 & 14 & M & 34 & 17 & 4 & M & 37 & 10 & 14 & F & 25 & 2 \\
\hline
\end{tabular}




\begin{tabular}{c|c|c|c|c|c|c|c|c|c|c|c|c|c|c|c}
\hline 5 & $\mathrm{M}$ & 39 & 18 & 15 & $\mathrm{M}$ & 38 & 15 & 5 & $\mathrm{M}$ & 25 & 3 & 15 & $\mathrm{~F}$ & 31 & 4 \\
\hline 6 & $\mathrm{M}$ & 38 & 15 & 16 & $\mathrm{~F}$ & 31 & 11 & 6 & $\mathrm{~F}$ & 39 & 7 & 16 & $\mathrm{~F}$ & 35 & 5 \\
\hline 7 & $\mathrm{M}$ & 49 & 27 & 17 & $\mathrm{M}$ & 36 & 16 & 7 & $\mathrm{~F}$ & 52 & 6 & 17 & $\mathrm{~F}$ & 26 & 2 \\
\hline 8 & $\mathrm{M}$ & 35 & 15 & 18 & $\mathrm{M}$ & 39 & 19 & 8 & $\mathrm{~F}$ & 37 & 11 & 18 & $\mathrm{~F}$ & 24 & 5 \\
\hline 9 & $\mathrm{M}$ & 39 & 15 & 19 & $\mathrm{M}$ & 56 & 34 & 9 & $\mathrm{~F}$ & 24 & 5 & 19 & $\mathrm{~F}$ & 26 & 2 \\
\hline 10 & $\mathrm{M}$ & 47 & 17 & & \multicolumn{1}{|c}{$\ldots \ldots$} & & 10 & $\mathrm{~F}$ & 26 & 2 & & \multicolumn{2}{c}{$\ldots \ldots$} \\
\hline
\end{tabular}

Experimental Equipments. (1)Experimental car: Home cars. (2) Driver adaptive testing system record the driver's night visual acuity, dynamic visual acuity, stereoscopic vision, depth perception , color discrimination, a complex reaction , manipulation skills, speed estimation, etc. (3) SIM head-mounted eye tracker record the driver's eye movement data. (4) Biopac MP150 Physiological Detector, record the driver's ECG Database and the Physiological parameter about the body moves the change intensity.

Experimental Routes. Select the city roads, rural roads, freeways.

Experimental Procedures. (1)Static detection data derived from the usual accumulation of the driver's detection in the laboratory. (2) Dynamic test. The driver to wear an eye tracker and ECG equipment, setting up synchronization, and data collected 2 hours in each road.

\section{Experimental data analysis}

(1) Static detection data analysis. Test data as shown in Table 2.and Figure 1. Physiological and psychological indicators test data analysis shows that: 1) in the physiological quality parameters of occupational drivers are superior to non-occupational drivers, especially in dynamic visual acuity and stereoscopic vision;2) in terms of psychological quality, long-term full-time driving duties, the occupational drivers have developed a habit of multi - information processing complex traffic environment, skilled driving operation also makes manipulation skills and complex reaction items outstanding; Speed estimation value high to some extent, is due to the age and personality dictates, the description of the occupational drivers are more cautious, especially when the vehicle lateral crossing , to have more time and space to ensure safe passage.

Table 2. Driving the adaptive test data comparison

\begin{tabular}{|c|c|c|c|c|c|}
\hline \multirow{2}{*}{\multicolumn{2}{|c|}{ Project }} & \multicolumn{2}{|c|}{ Average value } & \multicolumn{2}{|c|}{ Standard reference values } \\
\hline & & $\begin{array}{c}\text { Non-occupationa } \\
\text { l driver }\end{array}$ & $\begin{array}{l}\text { Occupational } \\
\text { driver }\end{array}$ & $\begin{array}{c}\text { Non-occupational } \\
\text { driver }\end{array}$ & $\begin{array}{l}\text { Occupational } \\
\text { driver }\end{array}$ \\
\hline \multirow{4}{*}{ psychological } & $\begin{array}{l}\text { night visual } \\
\text { acuity }\end{array}$ & 4.0 & 1.8 & \multicolumn{2}{|c|}{ reaction time: $<5 \mathrm{~s}$} \\
\hline & $\begin{array}{c}\text { dynamic visual } \\
\text { acuity }\end{array}$ & 0.45 & 0.9 & \multicolumn{2}{|c|}{ reaction time: $0.2 \sim 1.5 \mathrm{~s}$} \\
\hline & $\begin{array}{l}\text { stereoscopic } \\
\text { vision }\end{array}$ & 6.4 & 8.6 & \multicolumn{2}{|c|}{ Evaluation rating:4 9 } \\
\hline & depth perception & 14.8 & 11.5 & $\begin{array}{c}\text { Absolute } \\
\text { error: }<25 \mathrm{~mm}\end{array}$ & $\begin{array}{c}\text { Absolute error: }< \\
22 \mathrm{~mm}\end{array}$ \\
\hline \multirow{3}{*}{ Physiological } & $\begin{array}{l}\text { a complex } \\
\text { reaction }\end{array}$ & 3.5 & 1.6 & $\begin{array}{c}\text { Reaction times by } \\
\text { mistake: }<8\end{array}$ & $\begin{array}{l}\text { Reaction times } \\
\text { by mistake: }<5\end{array}$ \\
\hline & $\begin{array}{c}\text { manipulation } \\
\text { skills }\end{array}$ & 98 & 71 & $\begin{array}{c}\text { Reaction times by } \\
\text { mistake: }<130\end{array}$ & $\begin{array}{c}\text { Reaction times } \\
\text { by mistake: }<110\end{array}$ \\
\hline & speed estimation & 1732 & 1645 & $\begin{array}{l}\text { reaction time: } \\
500 \sim 2400 \mathrm{~ms}\end{array}$ & $\begin{array}{l}\text { reaction time: } \\
800 \sim 2500 \mathrm{~ms}\end{array}$ \\
\hline
\end{tabular}




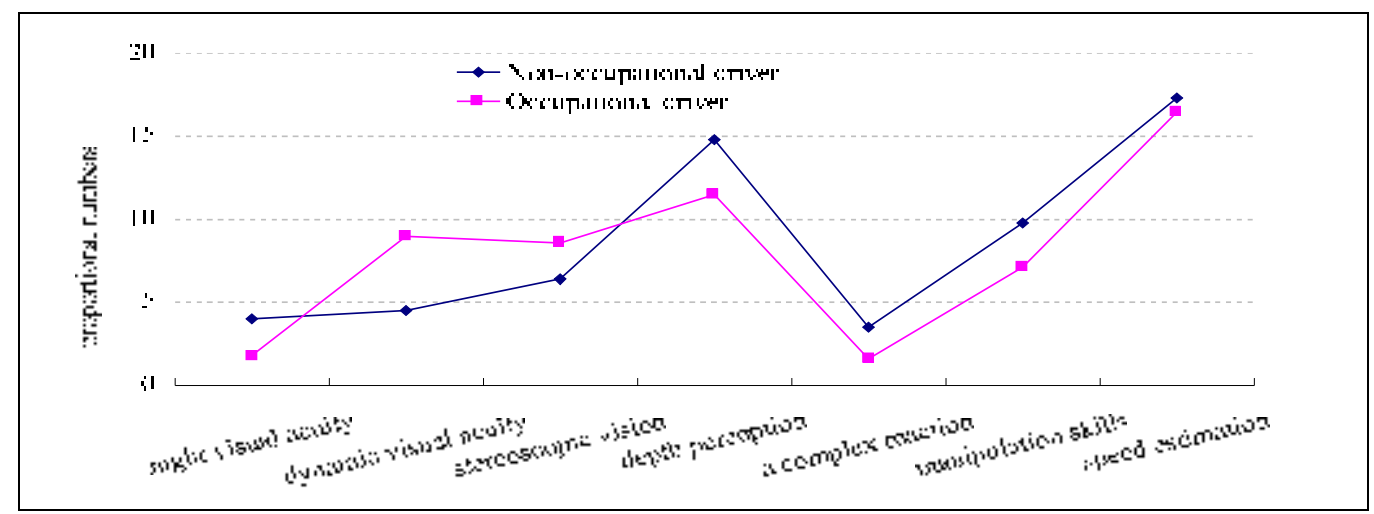

Figure 1. Driving the adaptive test data comparison

Psychological qualities analysis. Occupational driver and non-occupational driver psychological quality of test data as shown in Table 3.It can be seen from the table, occupational drivers qualified rate is much higher than the non-occupational drivers, and can be found complex reaction and speed estimation correlation measure greater, the better the skills of occupational drivers.

Table 3. Occupational and non-occupational driver psychological quality comparison

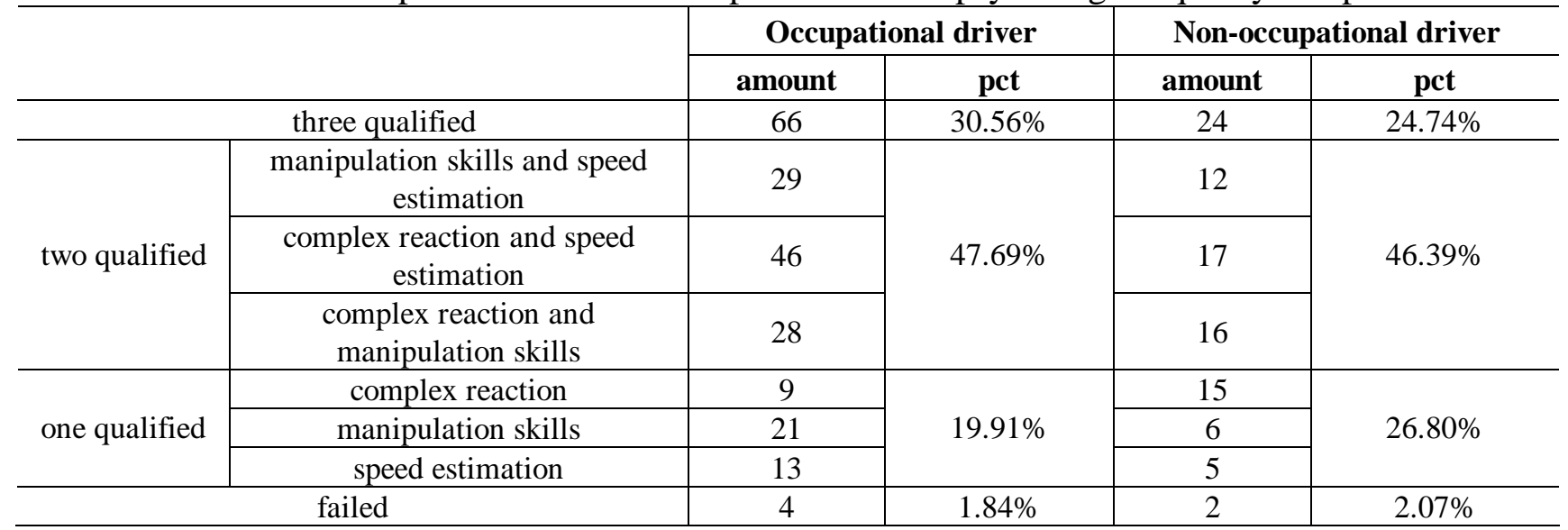

Physiological quality analysis. Occupational driver and non-occupational driver physiological quality of test data as shown in Table4.It can be seen from the table, the physiological quality of the occupational drivers are generally higher than non-occupational drivers, meanwhile, found that dynamic visual acuity, stereoscopic vision and depth perception related with greater,night visual acuity, stereoscopic vision and depth perception related with greater,but night visual acuity, dynamic visual acuity and stereoscopic vision related to the minimum,night visual acuity and dynamic visual acuity almost no correlation.

Table 4. Occupational and non-occupational driver physiological quality comparison

\begin{tabular}{|c|c|c|c|c|c|}
\hline & \multicolumn{2}{|c|}{ Occupational driver } & \multicolumn{2}{|c|}{ Non-occupational driver } \\
\hline & & amount & pet & amount & pct \\
\hline & four qualified & 111 & $51.39 \%$ & 22 & $22.68 \%$ \\
\hline \multirow{4}{*}{$\begin{array}{l}\text { three } \\
\text { qualified }\end{array}$} & $\begin{array}{l}\text { dynamic visual acuity, stereoscopic } \\
\text { vision and depth perception }\end{array}$ & 25 & \multirow{4}{*}{$33.80 \%$} & 16 & \multirow{4}{*}{$40.21 \%$} \\
\hline & $\begin{array}{l}\text { night visual acuity, stereoscopic } \\
\text { vision and depth perception }\end{array}$ & 31 & & 13 & \\
\hline & $\begin{array}{l}\text { night visual acuity, dynamic visual } \\
\text { acuity and depth perception }\end{array}$ & 11 & & 9 & \\
\hline & $\begin{array}{l}\text { night visual acuity, dynamic visual } \\
\text { acuity and stereoscopic vision }\end{array}$ & 6 & & 1 & \\
\hline \multirow[t]{3}{*}{$\begin{array}{l}\text { two } \\
\text { qualified }\end{array}$} & $\begin{array}{c}\text { night visual acuity and dynamic } \\
\text { visual acuity }\end{array}$ & 0 & \multirow[t]{3}{*}{$13.43 \%$} & 1 & \multirow[t]{3}{*}{$21.65 \%$} \\
\hline & $\begin{array}{l}\text { night visual acuity and } \\
\text { stereoscopic vision }\end{array}$ & 10 & & 2 & \\
\hline & $\begin{array}{l}\text { night visual acuity and depth } \\
\text { perception }\end{array}$ & 2 & & 5 & \\
\hline
\end{tabular}




\begin{tabular}{|c|c|c|c|c|c|}
\hline & $\begin{array}{l}\text { dynamic visual acuity and } \\
\text { stereoscopic vision }\end{array}$ & 4 & & 1 & \\
\hline & $\begin{array}{l}\text { dynamic visual acuity and depth } \\
\text { perception }\end{array}$ & 2 & & 7 & \\
\hline & $\begin{array}{l}\text { stereoscopic vision and depth } \\
\text { perception } \\
\end{array}$ & 11 & & 5 & \\
\hline \multirow{4}{*}{$\begin{array}{l}\text { one } \\
\text { qualified }\end{array}$} & night visual acuity & 0 & \multirow{4}{*}{$0.93 \%$} & 0 & \multirow{4}{*}{$15.46 \%$} \\
\hline & dynamic visual acuity & 0 & & 4 & \\
\hline & stereoscopic vision & 2 & & 3 & \\
\hline & depth perception & 0 & & 8 & \\
\hline & failed & 1 & $0.46 \%$ & 0 & $0.00 \%$ \\
\hline
\end{tabular}

Good vision is an essential key factor, especially the dynamic vision and stereoscopic vision, an important technical indicator to employ excellent driver for the future selection. Taking into account the physiological quality may increase with age occur recession, it is recommended that occupational drivers on a regular basis test carried out intensive training (such as: speed awareness intensive training and limb coordination training, etc.).

(2)Dynamic test data analysis. Through the analysis of experimental data on 38 drivers, the driver of the two types of eye movement characteristics in different road environments and ECG characteristics. Greater than the non-occupational drivers from Figure 2 that the average pupil area of the occupational driver in the pupil area of the urban road driver, indicating the maximum load in city driving; Figure 3 is a driver AOI area, Figure 4 and Figure 5 shows that the occupational driver's gaze region greater than the non-occupational drivers, non-occupational driver's gaze focused on the road in front of the watchful eye of both sides of the road.

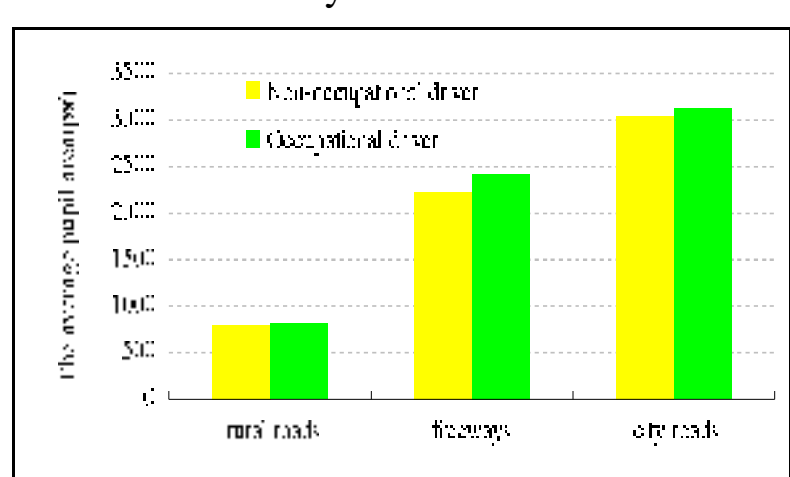

Figure 2.The average pupil area

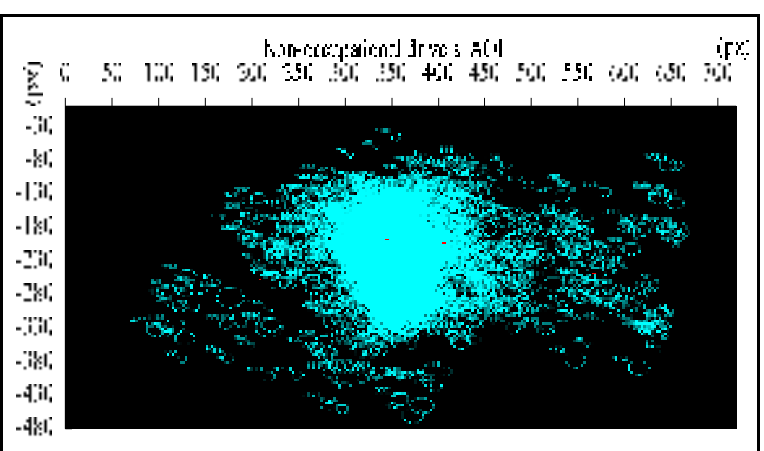

Figure 4. Occupational drivers' AOI

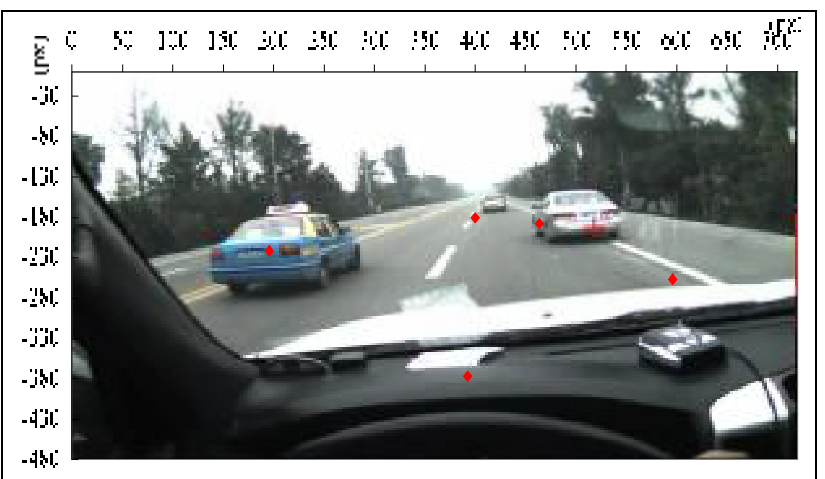

Figure 3.Drivers' AOI

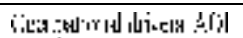
ॠrit

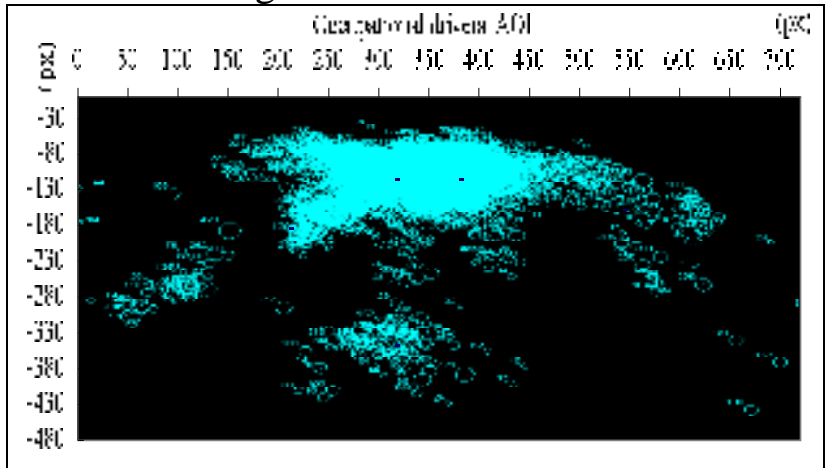

Figure 5. Non-occupational drivers' AOI

Form figure 6 , the non-occupational driver in the driving process, the increased rate of heart rate is higher than the occupational driver, indicating that the mental load they bear while driving; know from Figure 7 , in the urban road driving, the driver 's heart rate maximum rate of increase, the smallest in rural roads. 


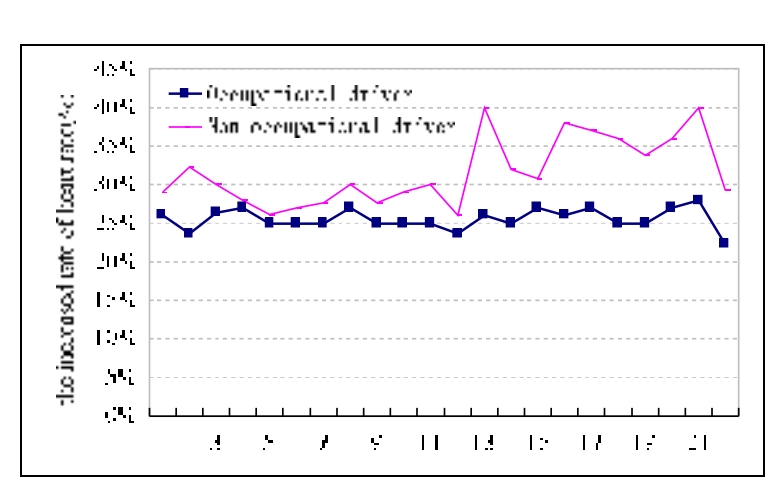

Figure 6. The increased rate of heart rate

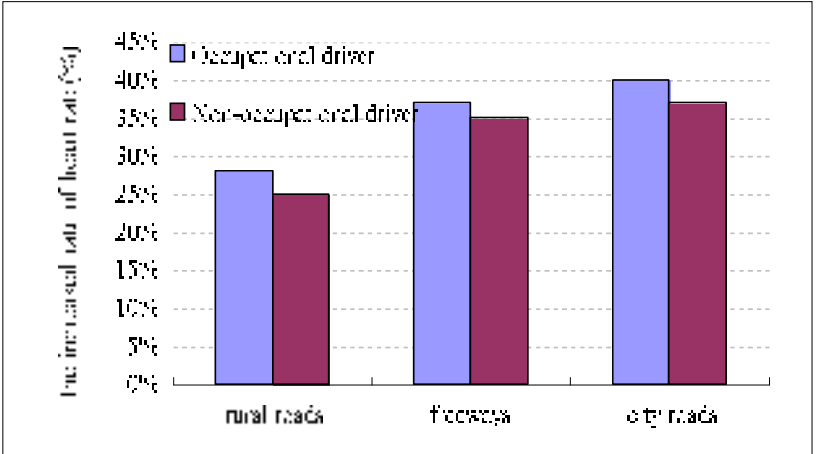

Figure 7. The increased rate of heart rate in different roads

\section{Conclusion}

Through static testing and dynamic tests, we found that the quality of occupational drivers' physiological and psychological qualities generally superior to non- professional drivers, professional drivers looking at the target distance and horizontal position with the traffic changes in the environment to be flexible to adjust.

Complex urban road traffic environment, occupational driver's looking at the points fall on a static target, the skilled driver can use peripheral vision and attention to a large number of moving targets , increase the speed and the traffic environment has become a stranger, skilled the driver of dynamic target Note video also will increase.

The driver can not once watched the watchful eye of a particular region, access to adequate information, it often requires repeated monitoring; professional drivers observe the central region of the main viewing area, also often concerned about the traffic conditions of the region on the left in order to overtake or for Road; professional drivers tend to the fixation point moved to the main viewing area on the left, in order to fully grasp the left and right sides of the traffic situation in the observation of the right mirror.

By comparing the driver's heart rate index in the different type of road, the results show that the degree of intellectual efforts of the driver have to pay in different road environments are different, in the city roads.

In the face, such as overtaking traffic incident, the driver will have a psychological pressure, higher risk perception coefficient, this danger signal stimulus passed so that the driver can increase alertness, but this stimulus is too often will accelerate and deepen driving members of the degree of fatigue, it is proposed should not be too frequent overtaking, especially at higher speed road.

\section{References}

[1] He Cao, Zhang Xiaogui.. "Accident analysis and prevention in the downlink of Xi-Han highway". Highways and Automotive Applications, (2008) NO.3,p60-63.

[2] HE Cao,CHEN Bin,WANG Jian Bo. "The Relationship of Linear Combination of Tunnel and Heart Rate Increase Rate". International Conference on Transportation Engineering, (2011).p.445-449.

[3] Zhao Jianyou,He Cao,Shi Yanni "Research on the Impact of Divers' heart rate on Longitudinal Slope of Freeway Tunnel” International Conference of Chinese Transportation Professionals, (2009).p.1451-1455 